\title{
Integrated analysis of retail trade areas: (1) techniques
}

\author{
H du Toit \\ C E Cloete \\ Department of Construction Economics \\ University of Pretoria, South Africa
}

\section{Keywords}

Market analysis, retail trade areas, central place theory, market saturation, retail demand potential.

\begin{abstract}
Traditional techniques for the analysis of trade areas (per capita approach, residual approach and analogue or share approach) oversimplify the relationship between population and expenditure, while pertinent variables that influence demand and potential are left unaccounted for. Inappropriate model specification, incomplete portrayal of market realities and faulty market analysis give rise to poor investment decision making. An integrated analysis of retail trade areas is proposed in this, the first of two papers. The analysis incorporates four proposed techniques, namely the Multi-Criteria Saturation Index (MCSI), Retail Diversification Index (RDI), Demand Density Analysis (DDA) and Growth Matrix (GM). Improvements to the analogue method are also proposed, including economic indicators to account for the time value of money.

In Part 2 of this paper a test for validity is developed, based on a comparison of actual versus forecast shopping centre sales data for twelve shopping centres in South Africa. The negligible difference observed between actual and forecast sales validates the proposed integrated approach.
\end{abstract}

Corresponding author: C E Cloete

Email addresses for corresponding author: chris.cloete@up.ac.za

First submission received: $13^{\text {th }}$ March 2018

Revised submission received: $15^{\text {th }}$ May 2018

Accepted: $18^{\text {th }}$ June 2018

\section{Introduction}

Market analysis is a key component of a sound real estate investment analysis process. Traditional market analysis techniques do not reflect complex trade area attributes and socio-economic realities, such as retail market structure, degree of diversity within the retail market structure, supply-demand saturation levels, the spatial distribution of demand and the composite effect of trade area growth variables on future asset performance. Pyhrr et al. $(1989,409)$ argues that faulty market analysis was a major contributor to the financial failure of real estate projects in the United States between 1980 and 1989.

Traditional techniques designed for the analysis of trade areas oversimplify the relationship between population and expenditure, while pertinent variables that influence demand and potential are left unaccounted for. Inappropriate model specification, incomplete portrayal of market realities and faulty market analysis give rise to poor investment decision making. The development of the proposed new methodology requires cognisance of the relationship between economic role players as portrayed in the Keynesian economic equilibrium equation Dernburg (1985, 9 \& 39 - 41); Lombard, Du Pisani and Steyn (1986, 15 - 17); Lombard, Stadler and Haasbroek (1989, 181 - 215); and Gnos and Rochon (2008, 10), but also of the complexities that characterise real estate and asset market interaction.

This paper proposes an improved methodology for the analysis of retail trade areas. The techniques that form part of the improved methodology include the Multi-Criteria Saturation Index (MCSI), the Retail Diversification Index (RDI), Demand Density Analysis (DDA) and Growth Matrix (GM). Selected improvements to the analogue model is also identified to account for the time value of money.

In Part II of this paper the validity of the proposed techniques is tested by comparing actual versus forecast shopping centre sales data for twelve shopping centres in South Africa.

\section{Literature}

Research on trade areas and demand modelling approaches applied in markets South Africa, Australia and the USA is presented in inter alia Kiel \& Haberkern (1998, 1138 - 1154), DiPasquale \& 
Wheaton (1996, 124 - 148), Clapp (1987, 35 - 44 \& 75 - 89), Davies (1977, 141 - 157), Applebaum \& Cohen (1961, 73 - 101) and Applebaum (1966, 127 - 141). The three dominant demand modelling approaches are, in brief:

Per capita approach

Residual approach

Analogue or share approach.

\section{Per Capita Approach}

The Retail Space Per Capita Approach is a rudimentary parameter-based technique that deploys generalized macro level norms and planning standards which define retail demand on a concentric circle basis. The concentric circle approach and parameter-based techniques are functionally integrated techniques. The former Transvaal Provincial Administration Retail Policy (Director of Local Government 1982 \& 1990, 34 - 41) serves as example. The policy is based on the theoretical model of Christaller (1933). In terms of this approach, a Community Centre is stated as a centre which typically measures between $15000 \mathrm{~m}^{2}$ and $30000 \mathrm{~m}^{2}$ and has a trade area radius of 2.5 kilometers. No distinction is drawn between primary and secondary trade areas. Tenant composition is not regarded in great detail. In terms of the aforementioned policy, retail demand is calculated as follows:

$0.4 \mathrm{~m}^{2}$ per capita within the $1.5-2.5 \mathrm{~km}$ radius

$0.8 \mathrm{~m}^{2}$ per capita within the $0.5-1.5 \mathrm{~km}$ radius

$1.2 \mathrm{~m}^{2}$ per capita within the $0-0.5 \mathrm{~km}$ radius.

Similar parameters apply to local convenience, neighborhood and regional shopping centres. These norms were said to be derived from established and relatively stable market environments - though no supporting research in this regard was documented. Existing trade area supply is subtracted from the parameter-based demand estimate. The difference yields the gap which, it is argued in terms of this approach, resembles the demand for new development.

The retail per capita approach is not renowned for accuracy and can be criticized for, inter alia, the fact that it considers the trade area as a closed system. The technique is, furthermore, income insensitive - i.e. the same parameters apply regardless of the socio-economic status of the market area. A third point of criticism against this technique is its reliance on simplistic concentric circle radii and the assumption that a store sells symmetrically on either side of its trade area. Christaller-like halfway breakoff points between centres, determined simply as a function of centre size and travel distance, are the norm. Christaller-based influences can still be observed in certain demand modelling approaches.

\section{Residual Approach}

The Residual Approach calculates the market gap as the difference between total trade area demand and trade area supply (Davies 1977). The technique requires a more refined approach to trade area delineation due to the phenomena of trade area overlap and multiple trade areas.

The supply of retail floor space within the primary trade area is factored but should ideally be refined as competitive retail floor space to exclude functionally dated and obsolete retail stock. Demand is expressed as a function of household income and expenditure per retail product type. Among the problems observed in practice include growth calculations focused on population (or household) growth, whilst economic growth indicators are not accounted for, therefore disregarding the time value of money. Clapp $(1987,36$ - 37) indicates that even towards the turn of the century, real estate market research practices in the USA continued to be influenced by Burgess and not by economics literature. These influences can also be observed in the residual model, which progressed from the simplistic parameterbased models. The calculation yields so-called net effective demand (total demand less total supply of retail floor space), i.e. the residual floor space (sqm) - a static value - that can theoretically be sustained by the market.

A first criticism of this approach is that it quantifies the size of a market gap as over- or undersupply but does so by analyzing the market as a closed system. Secondly, the approach calculates residual demand and not centre potential, optimum centre size or demand based centre composition. By virtue of the nature of the calculation, the approach is not responsive to the functional differentiation between 
shopping centres or store/outlet typologies. Aspects such as retail market structure and consumer demand distribution are not modelled. Differentiators such as centre age, location in relation to demand density are also not factored. The effects of multiple trade areas and trade area overlap are not modelled. All centres are regarded as equal competitors for the same amount of consumer spend within a predetermined market area - incorrectly assumed to be the trade area for all centres situated within it. The approach therefore embodies a typical 'cookie-cutter' calculation: total supply is deducted from total demand, regardless of functional differentiation between centres and their trade areas.

The approach stems from an era when urban development theory and market place environments were predominantly mono-centric with underdeveloped retail hierarchies and nodal structures. The approach is not suited to the analysis of complex, multi-nodal urban environments characterised by diverse and continually evolving retail formats.

\section{Analogue Approach}

The Analogue Approach (Applebaum 1966: 134 - 141), was refined from retailer models. These models superimposed customer origin data and sales values to comparable market areas in order to estimate expected capture rates, sales and store sizes. The analogue ('near twin') approach requires extensive time series data. The approach involves collaboration between the market analyst, developers and retailers over time and requires extensive experience and expert judgement. The analogue model was developed to respond to increasingly competitive market environments and requires a more systematic analysis of market supply and competition. Market demand can be quantified in a number of ways, including (Clapp 1987, 58 \& Pyhrr et al. 1989, 373 - 424):

expenditure per capita;

expenditure per household;

sales per square meter; or

sales per employee.

\section{Other Approaches}

Other approaches observed in practice includes site visitation models, Nelson's Microanalysis Technique, extensive consumer survey-based approaches and cartograms based on diffusion equations (e.g. Clapp 1987, 62 - 74; DiPasquale and Wheaton 1996, 124 - 148, Timmermans 1993, 343 - 377, Perales 2002 and Nicolas 2009). These approaches are designed to model site visitation as opposed to quantified shopping centre demand. Nicolas $(2009,24-25)$ provides an insightful disposition on cartograms - a technique that shapes geovision in accordance to, for instance, the purchase power of regions. Nonetheless, in terms of calculation and forecasting shopping centre demand, the analogue approach is generally applied.

\section{Methodology}

The improved methodology proposes the incorporation of four techniques, namely the MultiCriteria Saturation Index (MCSI), Retail Diversification Index (RDI), Demand Density Analysis (DDA) and Growth Matrix (GM). Selected localized economic indicators were simultaneously incorporated into the analogue model to account for the time value of money. A test for validity was developed, based on a comparison of actual versus forecast shopping centre sales data. These techniques were applied in demand calculations for proposed shopping centres that have since been developed and become operational. The difference between actual and forecast sales was observed in each instance as measure of accuracy for the proposed improved methodology for the analysis of retail trade areas.

The Multi-Criteria Saturation Index (MCSI) measures the degree of saturation or, conversely, latent potential (i.e. depth) in a particular market area. The basis for the evaluation is the total offering of shopping center floor size, as reflected by the country or region's retail classification data. The MCSI is neutral in respect of classification differences between countries/regions, which renders it suitable for inter-regional comparison. The MCSI suited to macro and meso-level analysis and, as such, could assist the investor in country and/or regional selection decisions. To account for the economic differences that underlie each of the geographic markets under consideration, the proposed MCSI incorporates gross 
domestic product (GDP) per capita - which is positively correlated with disposable household income (a primary driver of retail demand) - to establish purchase price parity between regions.

The Retail Diversification Index (RDI) is proposed to measure the degree of diversification or, conversely, concentration in a particular market area (i.e. structure). The basis for the evaluation is the relative size of retail classes, as reflected by the country or region's internal retail classification data. The index can be adapted to the retail classification of a country, region or trade area. The index value is neutral to retail hierarchical differences: the index measures the spread of centres or floor space between the respective retail classes and neutralises the effects of hierarchies with dissimilar classifications. Consequently, the score achieved by a particular geographic market area is directly comparable with that of another market area, regardless of classification idiosyncrasies.

Trend surface mapping is a GIS enabled technique that permits mapping or modelling an observed surface by fitting statistical attributes, planes or curves with known geometric properties. Trend surface mapping per se is not a new technique (Box 1954, 16 - 60, Chorley \& Haggett 1968, 195 - 217 and Peterson 1974, 338 - 342). Country and/or regional selection is refined by means of the proposed Demand Density Analytical technique. Demand density analysis translates official localized income data (sourced from the official Census statistical bureau) for known statistical entities, known in SA as 'sub-places', into map-able consumer-based retail demand, applying trading density as conversion factor (i.e. spatial distribution of consumer demand). The technique integrates quantitative and GIS approaches to trade area analysis. This technique may assist the investor to identify geographic demand concentrations which, in turn, identifies demand opportunities of highest concentration. As such, the results reflect investment possibilities geographically.

Trade area analysis is supplemented with another proposed technique, the Growth Matrix (GM). Once a site-specific and trade area-based market analysis has been performed, careful consideration needs to be afforded to the complex interplay between and effects of socio-economic growth indicators on asset performance over time. Localized growth indicators often possess a hidden longer-term prognosis for asset appreciation - determined by rental income growth, i.e. annual escalations. The Growth Matrix is a quantitative instrument that graphs the combined effect of market growth indicators, including real growth in aggregate consumer spend, against minimum required and inflation adjusted trading density growth that would be required to sustain market related rental escalations over time. Demographics in itself do not explain the complexity of trade area growth. Trade area analysis is therefore more comprehensively informed by local economic growth indicators in time series format. In addition to population and household growth, the technique incorporates the following inflation adjusted time series growth indicators to account for non-demographic trade area growth attributes:

local economic growth and labour

local trade sector growth

disposable income growth

final consumption expenditure growth.

The techniques are complementary in progressively more focused analyses, from macro to local level:

Multi-Criteria Saturation Index - macro and meso-level analysis, i.e. country and region comparison and selection;

Retail Diversification Index - macro, meso and trade area analysis, i.e. suitable for regional and trade areabased comparison;

Demand Density Analysis - macro, meso and trade area analysis, i.e. suitable for region and site selection; Growth Matrix - trade area analysis, i.e. suitable for site-specific and trade area-based evaluation.

\section{Data analysis}

\subsection{Multi-Criteria Saturation Index (MCSI)}

A comparative static analysis was conducted for 7 randomly selected countries, including Australia, China, France, Malaysia, South Africa, Turkey and the United States of America (ICSC 2014 - 2017). Development of the proposed multi-criteria saturation index entailed the following steps: 
- Compile a synthesized table, indicating the shopping center floor space per capita for each country or region;

- Tabulate the purchase power parity (PPP) gross domestic product (GDP) per capita for each country or region;

- Calculate the GDP/capita to GLA/capital ratio for a selected year;

- Calculate the MCSI;

Rank results.

Table 2 provides a summary of the shopping center floor space per capita for seven countries 2009 to 2014 (2015 ICSC data is not available for all countries).

\begin{tabular}{|l|l|l|l|l|l|l|l|}
\hline Country & 2009 & 2010 & 2011 & 2012 & 2013 & 2014 & \multicolumn{1}{l|}{ Change per annum (\%) } \\
\hline United States & $2.220^{*}$ & 2.230 & 2.220 & 2.210 & 2.200 & 2.199 & -0.19 \\
\hline Australia & 0.910 & 0.900 & 0.920 & 0.934 & 0.940 & 1.040 & 2.71 \\
\hline China & 0.440 & 0.460 & 0.470 & $0.480^{*}$ & $0.490^{*}$ & $0.500^{*}$ & 2.59 \\
\hline South Africa & 0.342 & 0.331 & 0.365 & 0.399 & 0.440 & 0.427 & 4.54 \\
\hline Malaysia & 0.320 & 0.333 & 0.362 & 0.375 & $0.394^{*}$ & 0.432 & 6.19 \\
\hline France & 0.225 & 0.232 & 0.234 & 0.236 & 0.240 & 0.238 & 1.13 \\
\hline Turkey & 0.079 & 0.088 & 0.102 & 0.114 & 0.124 & 0.126 & 9.79 \\
\hline
\end{tabular}

Table 2: Retail Floor Space per Capita for selected countries, 2009 - 2014

Source: ICSC Country Fact Sheets 2014 - 2017

Note: $\quad{ }^{*}$ Estimate

Comparatively lower to negative levels of change can be observed in the developed countries of the United States $(-0.19 \% / a)$, France $(1.13 \% / a)$ and Australia $(2.71 \% / a)$. Comparatively higher rates of annual change can be observed in developing markets such as Turkey $(9.79 \% / a)$, Malaysia (6.19\%/a) and South Africa $(4.54 \% / a)$. The data indicates that, with the effects of purchase power factored, direct comparison of the $\mathrm{m}^{2} /$ capita values between countries is inappropriate. In order to directly compare markets, an adjustment for purchase power parity (PPP) has to be made.

The United States market was assumed as basis for establishing the parameters of a comparatively mature and developed market, at or near saturation. On this basis, a PPP adjusted floor space demand parameter for each of the remaining 6 countries was calculated. Table 3 provides a summary of purchase power parity adjusted per capita floor space demand parameters for the 7 countries analyzed.

\begin{tabular}{|l|l|l|l|l|}
\hline Country & $\begin{array}{l}\text { Unadjusted } \\
\mathrm{m}^{2} \text { per capita parameter }\end{array}$ & $\begin{array}{l}\text { GDP per Capita } \\
\text { (PPP adjusted) }\end{array}$ & \multicolumn{1}{l}{$\begin{array}{l}\text { Adjustment } \\
\text { Ratio }\end{array}$} & \multicolumn{1}{l}{$\begin{array}{l}\text { PPP Adjusted } \mathrm{m}^{2} \text { per capita } \\
\text { parameter }\end{array}$} \\
\hline United States & 2.199 & 55800 & 1.000 & 2.2 \\
\hline Australia & 1.040 & 47800 & 1.167 & 1.2 \\
\hline China & 0.500 & 13400 & 4.164 & 2.1 \\
\hline South Africa & 0.427 & 13400 & 4.164 & 1.8 \\
\hline Malaysia & 0.432 & 25700 & 2.171 & 0.9 \\
\hline France & 0.238 & 41700 & 1.338 & 0.3 \\
\hline Turkey & 0.126 & 20100 & 2.776 & 0.3 \\
\hline
\end{tabular}

Table 3: Adjusted Floor space per capita parameter per country, 2014 
The difference between the PPP adjusted per capita floor space demand parameter and the original floor space supply parameter (Table 2) serves as measure of latent potential. The markets that reveal the greatest gap between the adjusted and unadjusted parameter are, in order: South Africa, China and Malaysia. These three markets offer the greatest relative scope for retail market growth and densification in the form of new supply-side development.

\subsection{Retail Diversification Index (RDI)}

The RDI technique was applied to the same sample of countries identified above and then to a selection of small cities and large towns within South Africa.

The proposed technique entails the following steps:

- Compile a synthesized data table, indicating the respective shopping centre categories as well as the square meter and percentage spread across the spectrum;

- Rank the categories from smallest to largest;

- Calculate minimum and maximum index scores by, respectively, perfectly equal spread and perfectly unequal spread;

- Calculate the minimum-maximum difference and denominator;

- Cumulative scoring;

- Cumulative score, less minimum-maximum difference;

- Index calculation (result of 6 , divided by denominator).

The RDI value of $62.2 \%$ for Malaysia (Table 4) reflects a relatively concentrated and imbalanced market structure. There are only three categories in the Malaysian retail structure, of which one category dominates with a contribution of $72.2 \%$. The United States retail market revealed an equally high RDI value of $60.6 \%$. In the US market, two categories together contribute $56.2 \%$ to the industry: neighborhood centres with a contribution of $30.8 \%$ and community centres contributing $25.4 \%$. Although these two market segments are comprised of a proportionally larger number of smaller centres, the high RDI reflects on a proportionally concentrated and imbalanced retail market structure. The RDI values for South Africa $(43.2 \%)$, Australia $(42.9 \%)$ and Turkey $(30.3 \%)$ are comparatively low, indicating a proportionally more diversified and balanced retail market structure in these countries.

\begin{tabular}{|c|c|c|c|c|c|}
\hline Country & $\begin{array}{l}\text { Standard } \\
\text { Deviation }\left(\mathrm{m}^{2}\right)\end{array}$ & $\begin{array}{l}\text { Percentage } \\
\text { Deviation }\end{array}$ & $\begin{array}{l}\text { Economic } \\
\text { Classification }\end{array}$ & RDI Value & RDI Classification \\
\hline Australia & 2231804 & $8.9 \%$ & Developed & 42.9 & More diverse \\
\hline France & 2660945 & $16.8 \%$ & Developed & 55.1 & More concentrated \\
\hline Malaysia & 4574435 & $33.9 \%$ & Developing & 62.2 & More concentrated \\
\hline South Africa & 2063592 & $9.0 \%$ & Developing & 43.2 & More diverse \\
\hline Turkey & 1305344 & $12.0 \%$ & Developing & 30.3 & More diverse \\
\hline United States & 75986419 & $10.7 \%$ & Developed & 60.6 & More concentrated \\
\hline
\end{tabular}

Table 4: Summary of RDI Country Index Values and Economic Status

By inference, the USA RDI value suggests that future development opportunities will, in all probability, hinge on:

First, niche opportunities and redevelopments that may see the addition of specialised retail formats to existing nodes;

To a lesser extent, general (i.e. more conventional) retail formats as part of new nodes in high growth geographic markets, e.g. areas that experience high rates of sustained urbanization through inmigration create opportunities for demand led growth and the emergence of new nodes - although the developed market status would suggest that such remaining opportunities of scale might be comparatively limited; and untapped geographic markets, e.g. new mining towns, new airports, tourist 
destinations, etc - in a mature market (i.e. developed economy), such opportunities may continue to emerge, but could be expected to be limited and highly localized.

The Malaysian retail structure is highly concentrated in a small number of categories. Given the developing status of the economy, appreciable opportunities for network expansion and diversification exist.

In the developing economies of South Africa and Turkey, both markets reveal relatively balanced and diversified retail structures. The relatively diverse market structure suggests that a response to retail opportunities has already occurred in these developing economies - more so when compared to Malaysia - and market saturation should be monitored. Future opportunities for growth in generalized retail formats, i.e. retail network expansion, will be closely correlated with localized economic growth prospects. Network expansion, in turn, create new opportunities for network densification (i.e. diversification) over time. As these markets mature, redevelopment opportunities may emerge. The developed Australian economy offers a relatively well diversified and balanced retail structure. Aspects such as economic growth and market size will determine the rate and scale of network expansion. Continued structural diversification is likely to occur.

The selection of small cities and large towns within South Africa included Nelspruit (Mbombela), Witbank (eMalahleni), Bushbuck Ridge, Kimberley (Sol Plaatje), Mafikeng (Mahikeng), Klerksdorp (Matlosana), Pietersburg (Polokwane), Rustenburg and Soweto. This selection corresponds with the location of shopping centres analyzed in the test for validity.

The results for the sample of nine (9) towns and cities are summarised in Table 5.

\begin{tabular}{|l|l|l|l|}
\hline \multicolumn{2}{|l}{ Area } & RDI & \multicolumn{2}{l|}{ Nodal Ratio* } & Floor Space parameter (sqm/capita) \\
\hline Polokwane & 68.4 & 1.2 & 1.07 \\
\hline Rustenburg & 71.6 & 1.0 & 0.49 \\
\hline Nelspruit & 72.9 & 0.8 & 2.62 \\
\hline Witbank & 74.2 & 0.6 & 0.82 \\
\hline Kimberley & 76.3 & 1.0 & 0.50 \\
\hline Klerksdorp & 78.4 & 0.5 & 0.62 \\
\hline Soweto & 83.4 & 0.2 & 0.18 \\
\hline Mafikeng & 86.5 & 0.3 & 0.59 \\
\hline Bushbuck Ridge & 93.0 & 0.2 & 0.49 \\
\hline AVERAGE & & & 0.82 \\
\hline
\end{tabular}

Table 5: RDI Comparison for selected Areas in South Africa

Source: Calculations based on SACSC 2015/16

*Note: Nodal Ratio - calculates the ratio of centres at each level of the hierarchy in relation to centres in the level of the hierarchy directly above; then averages all values

The following observations can be made in regard to the modelled research findings:

The average shopping centre supply per capita across the sample of 9 markets is $0.82 \mathrm{~m}^{2}$ per capita.

An inverse correlation can be observed between the RDI value and the nodal ratio, affirming that a higher degree of concentration in the retail structure (i.e. less structurally divers) can be associated with lower levels of nodal formation - inferences can be made in respect of area economic characteristics, i.e. developed and mature versus developing, the expected level of competition, market diversification opportunities, etc. 
The lowest nodal ratios and square metre per capita ratios can be observed in former township and rural areas, including Soweto, Mafikeng and Bushbuck Ridge - which is indicative of appreciable latent market potential.

Nelspruit has the highest shopping centre supply per capita $\left(2.62 \mathrm{~m}^{2}\right.$ per capita) but the town is served by an extensive secondary regional catchment - which is not reflected in the RDI.

Disparities can be observed between urban areas and areas with a distinct rural character.

The diverging range of parameters suggest inherent latent market capacity in various markets.

\subsection{Demand Density Analysis}

The RDI and MCSI offer insight into market structure and saturation levels but neither technique offers insight into the spatial distribution of demand. Trend surface mapping ads a spatial dimension to market data. The demand density analysis is proposed as such an approach.

Census household income data per sub-place is the basis for the demand density analysis. A sub-place is the geographic unit for which Statistics South Africa releases census data. Demand density analysis proposed in this paper entails the following steps:

Compile a database with census-based income per sub-place for a selected market area;

Adjust for growth;

Calculate retail spend (in SA Rands) per sub-place;

Convert retail spend to demand (turnover density)

Map results.

Quantitative results are database centered and extensive. Figure 1 provides an extract of the provincial income database. Figure 2 provides an extract income to demand density conversion database.

Results of a GIS based demand density analysis for Mpumalanga Province in South Africa are illustrated in Figure 3 and 4. GIS technology offers a variety of presentation formats. This paper illustrates 2dimensional and 3-dimensional options. 


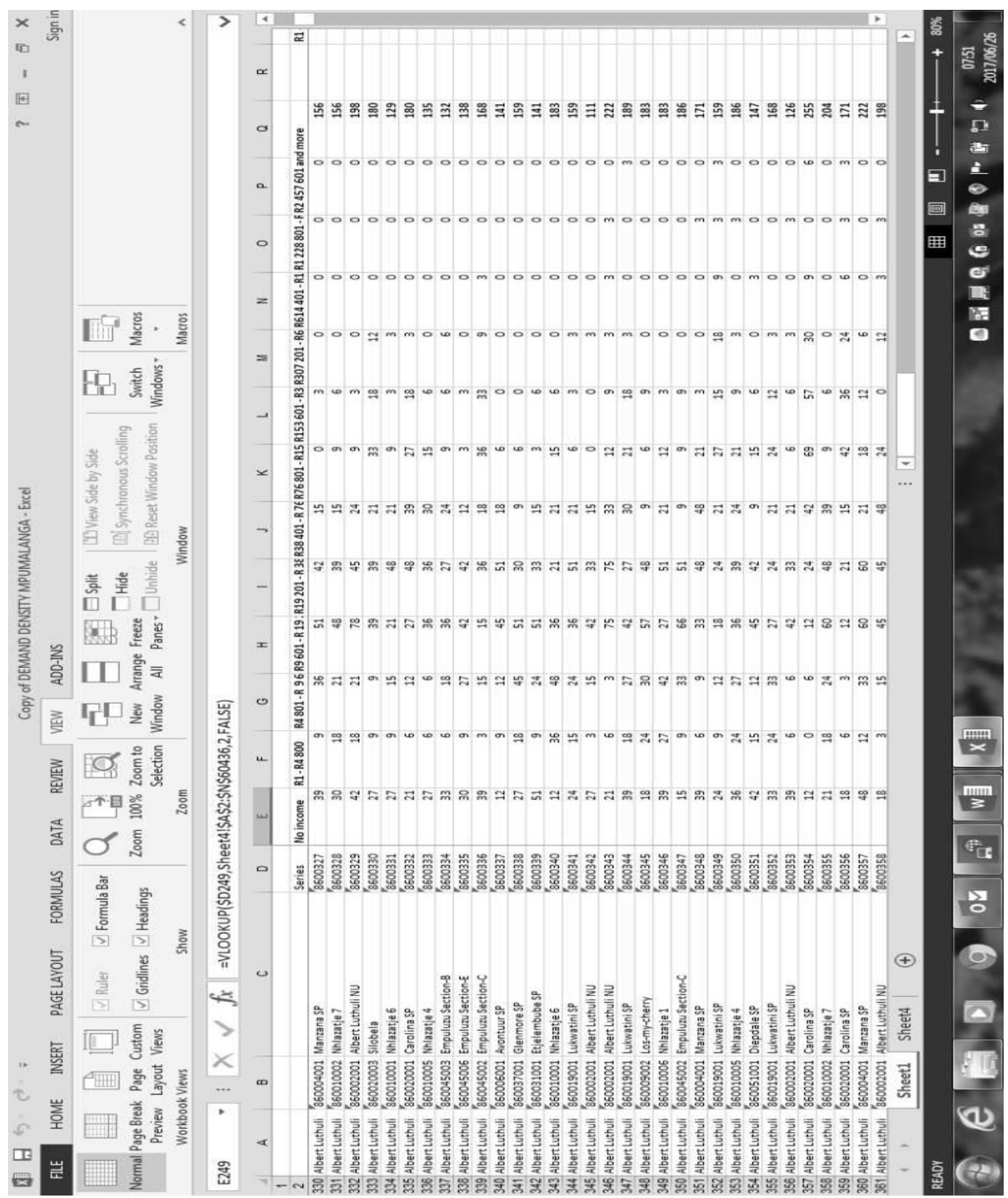

Figure 1: $\quad$ Mpumalanga Province Income database extract, 2011 


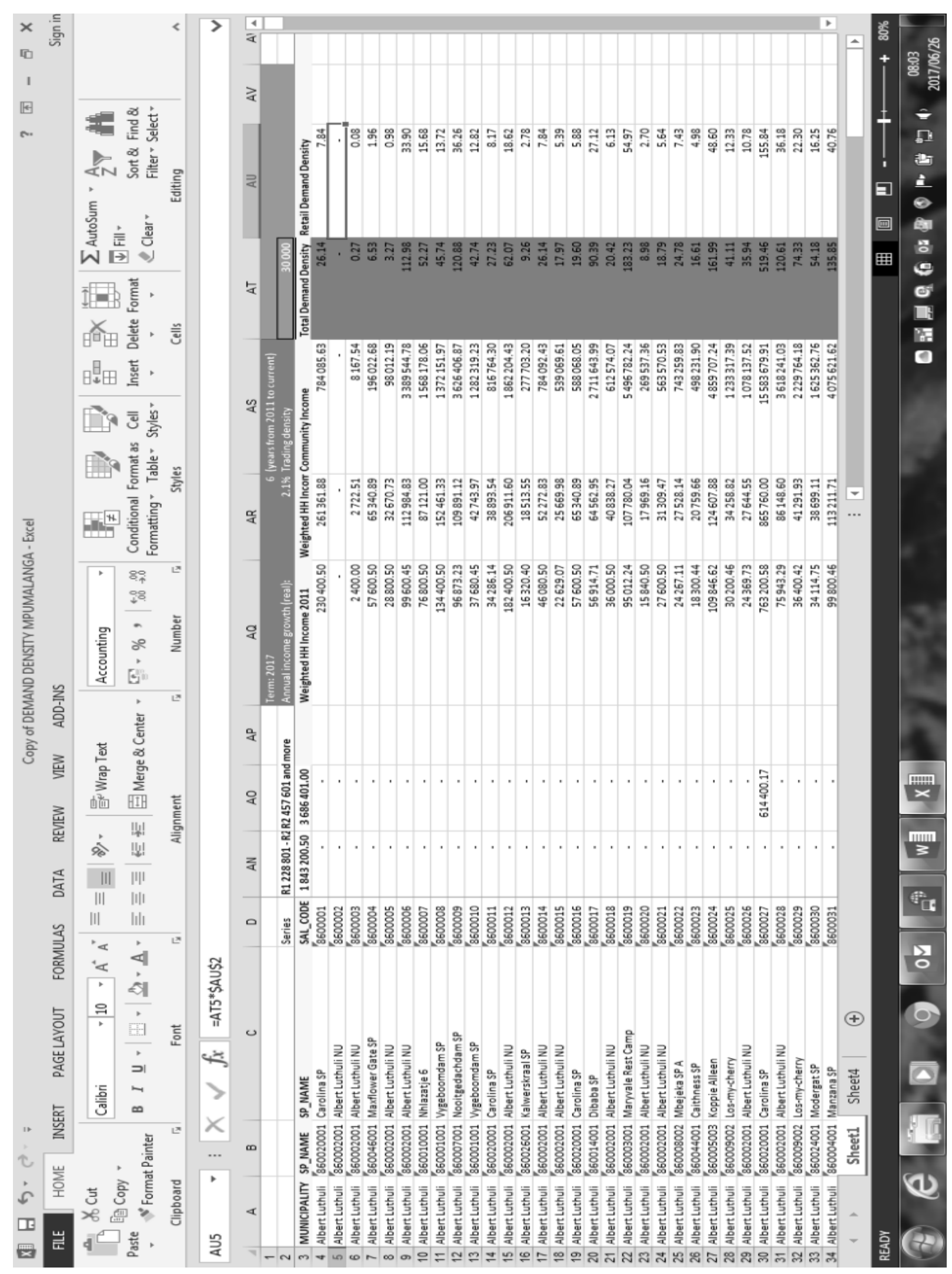

Figure 2: $\quad$ Mpumalanga Province Income-to-Demand-Density Conversion Database extract, 2017 


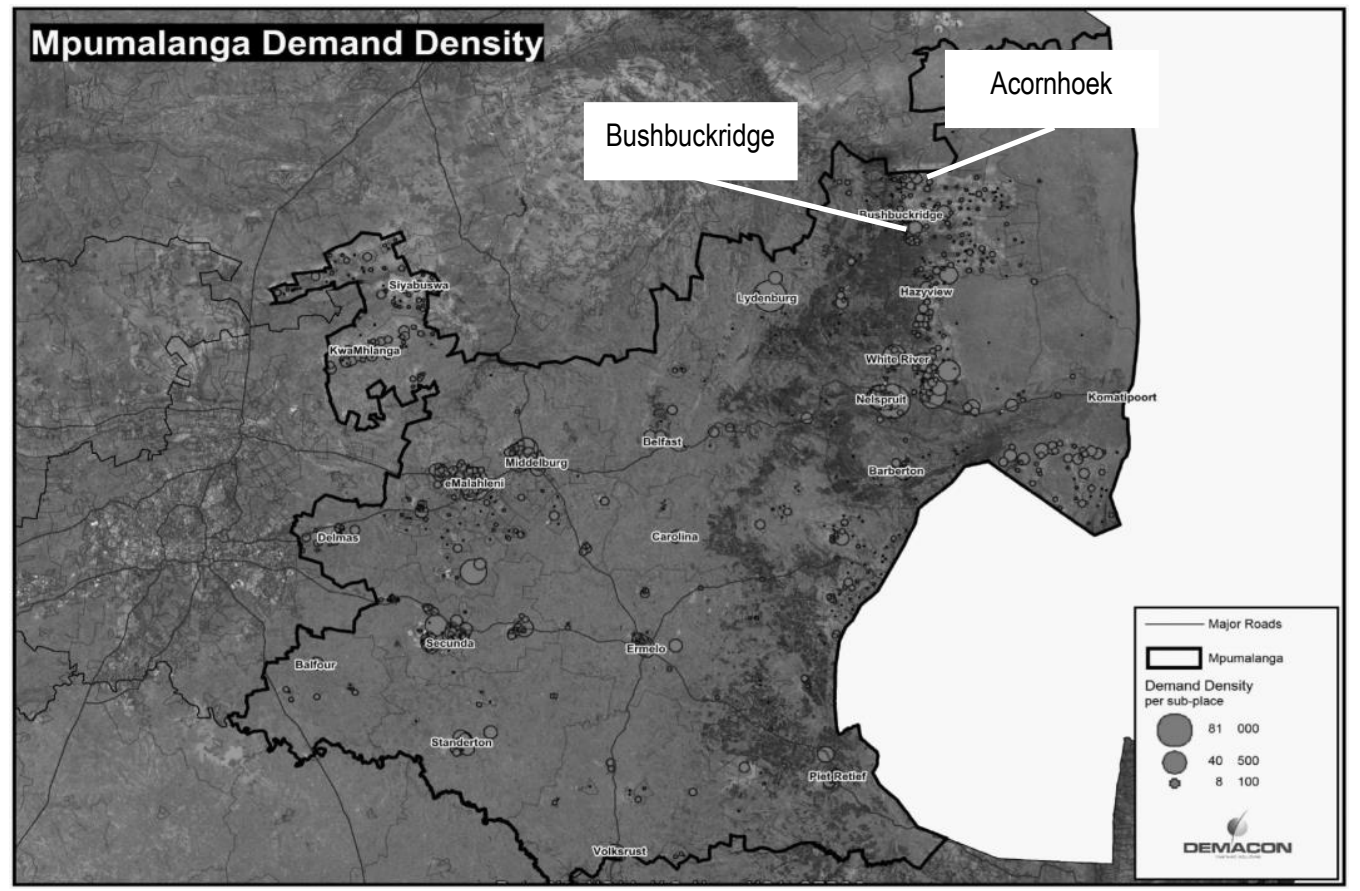

Figure 3: $\quad$ Mpumalanga Province 2-Dimensional Demand Density Analysis, 2015

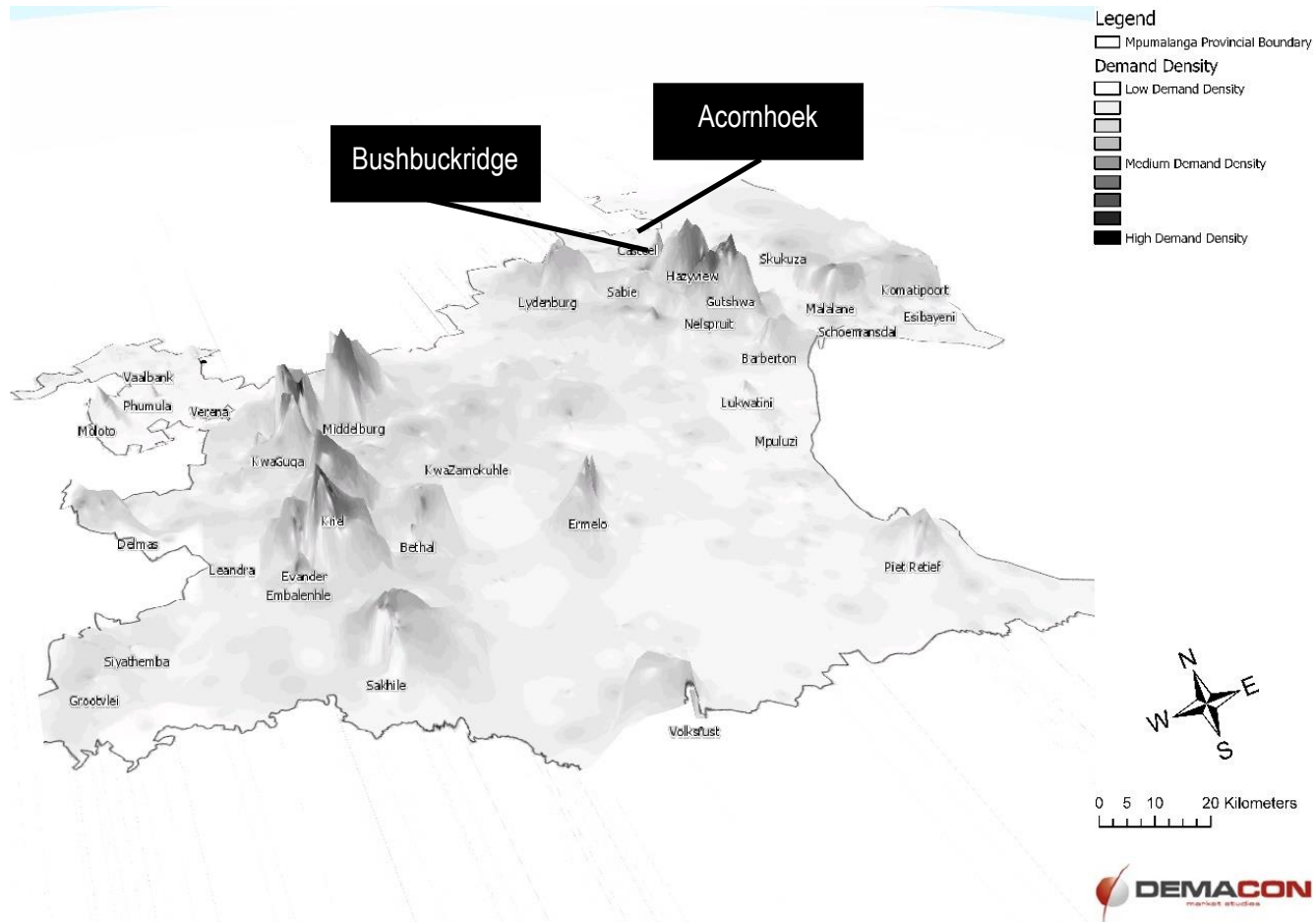

Figure 4: $\quad$ Mpumalanga Province 3-Dimensional Demand Density Landscape, 2017

Figures 3 and 4 indicate that demand is concentrated in and around certain urban centres, including Nelspruit, Middelburg, Witbank (eMalahleni) and Secunda. A comparatively more dispersed demand pattern can be observed in the populous, although relatively lower income rural areas of KwaMhlanga, Nkomazi (south of Komatipoort) and Bushbuckridge. Bushbuckridge and Acornhoek are indicated in Figure 3 and 4 to illustrate the Growth Matrix discussion. 


\subsection{Growth Matrix}

The Growth Matrix was developed to provide insight to the impact of trade area growth attributes on asset performance (specifically income generation potential) over time. Two illustrative examples are analysed, namely sites in Bushbuckridge CBD and Acornhoek.

Market growth is not simplistically determined by household growth, but also by income growth (and by implication household expenditure and disposable income growth), as well as minimum required trading density growth (which should account for the applicable inflation environment, i.e. 5-6\% annual consumer price inflation in South Africa. Real growth of $3 \%$ is required to yield sustainable rental escalations of $8 \%-9 \%$ (an absolute minimum of $7 \%$ has been observed in presently market conditions). Inflation adjusted consumer spend and trading density growth was calculated for both areas (Figure 5 and 6).

On face value, both markets are growing. Similarly, in both instances a widening gap between consumer expenditure on retail goods and services, and trading densities can be observed. It is this widening gap that creates the impression to retailers that the market is growing rapidly. In Bushbuckridge, long term household growth calculates to $0.65 \%$ per annum, final consumption expenditure growth averages $0.4 \%$ per annum over the long term and disposable income growth averages $1.0 \%$ per annum. In Acornhoek, long term household growth averaged $1.0 \%$ per annum, final consumption expenditure growth averaged $1.2 \%$ per annum over the long term and disposable income growth averaged $0.8 \%$ per annum.

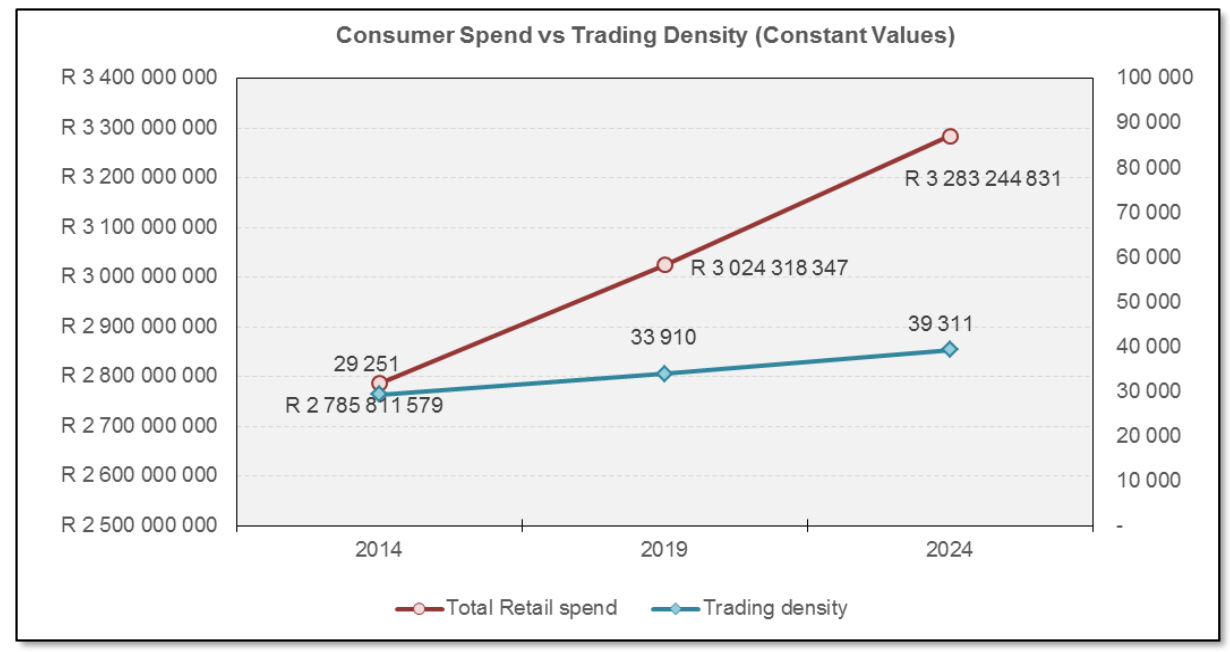

Figure 5: $\quad$ Bushbuck Ridge Consumer Spend and Trading Density Growth, 2014 - 2024

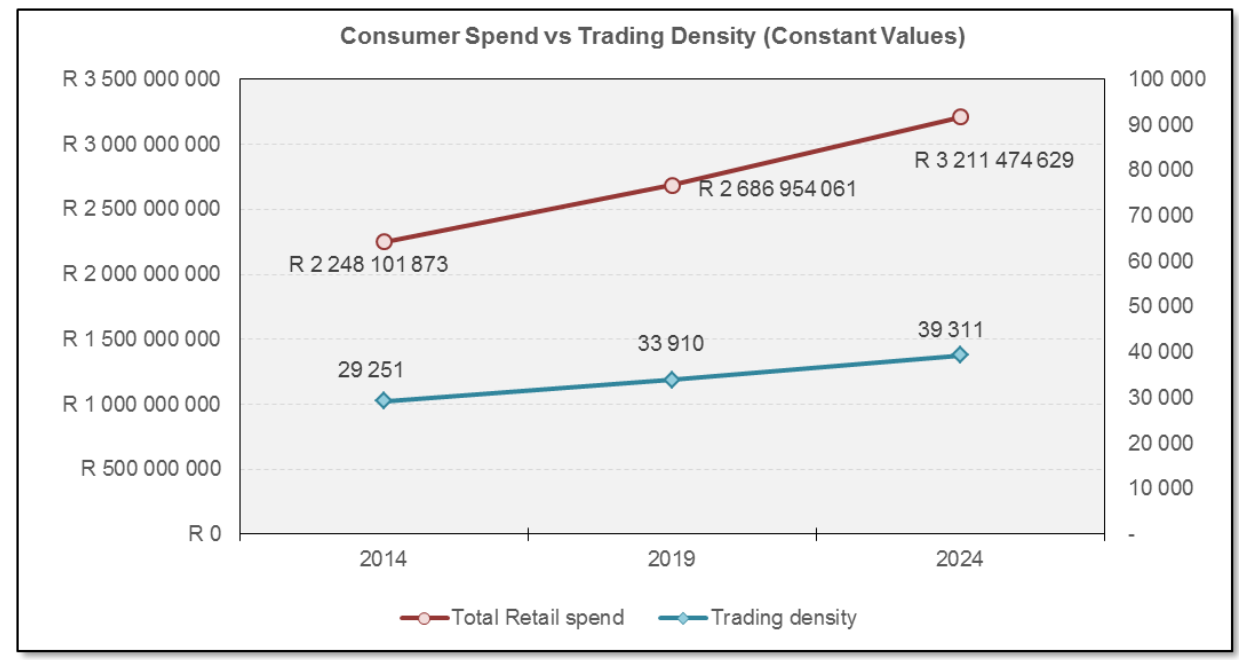

Figure 6: $\quad$ Acornhoek Consumer Spend and Trading Density Growth, 2014 - 2024 
Retail demand is calculated by dividing an annualized benchmark turnover density into annual consumer spend. Figure 7 and 8 illustrate extracts from the growth matrix model.

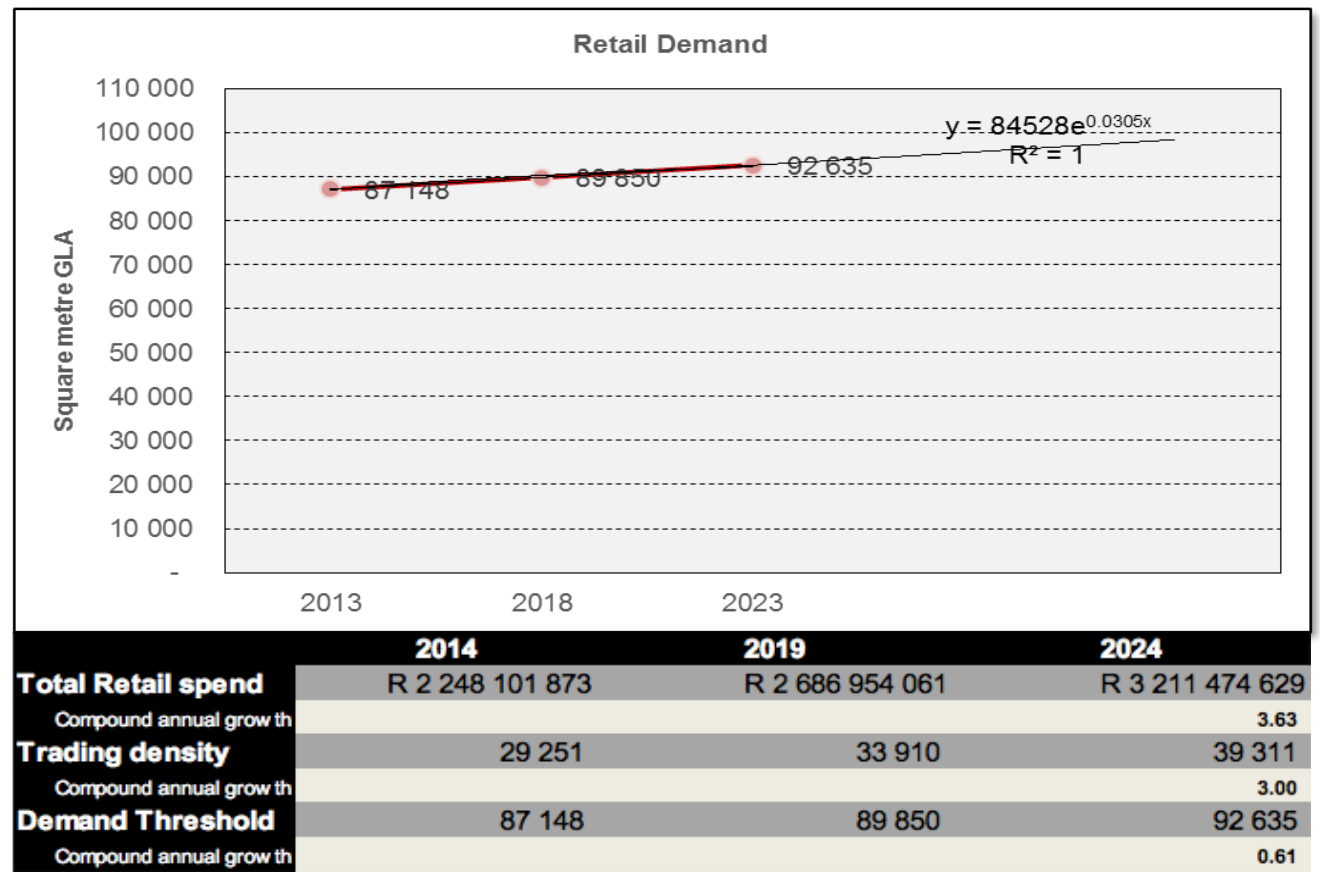

Figure 7: Bushbuckridge Retail Demand Summary, 2014 - 2024

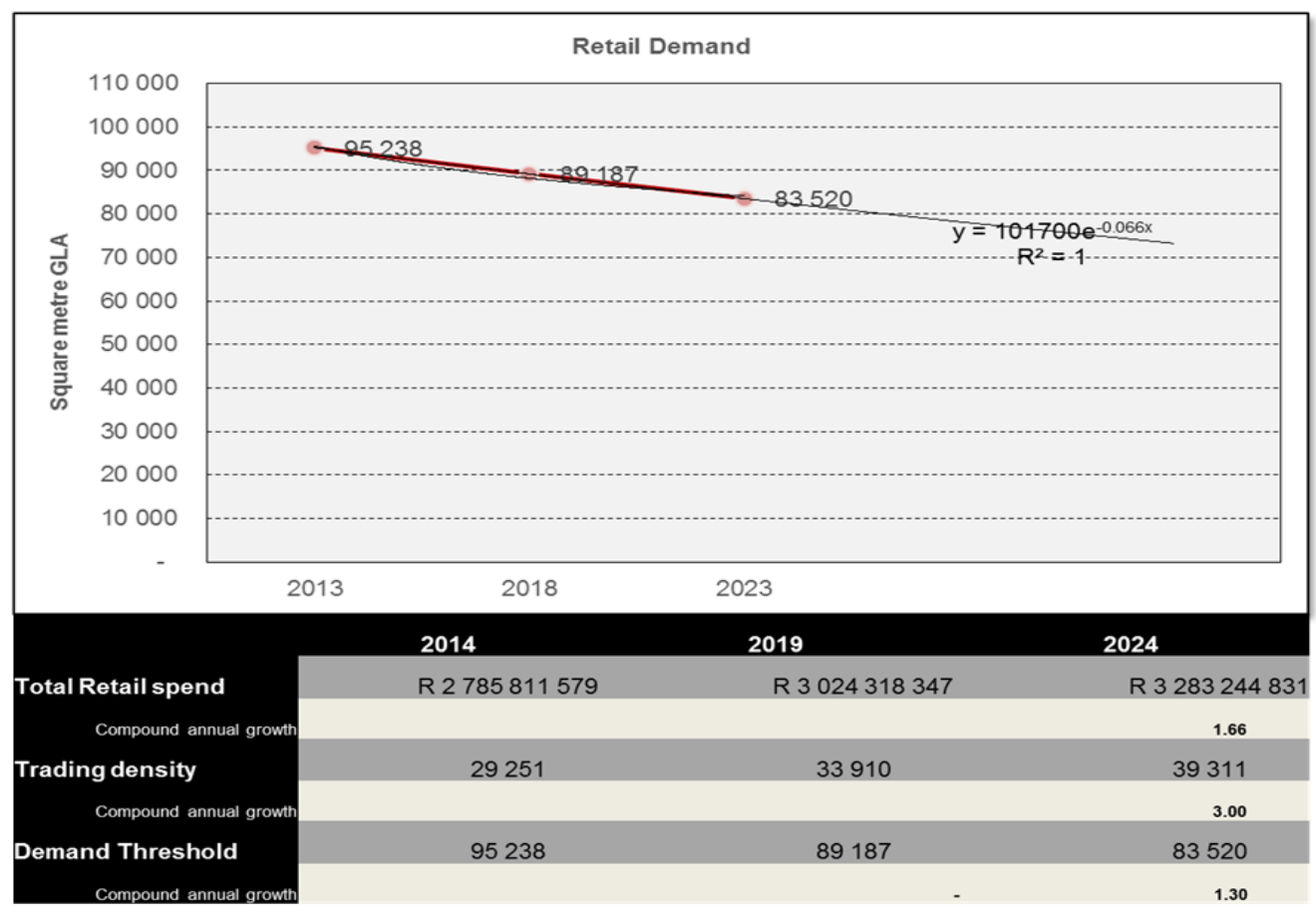

Figure 8: Acornhoek Retail Demand Summary, 2014 - 2024

In the Bushbuckridge market, the combined effect of household and disposable income growth translates into an annualized $1.66 \%$ increase in household retail spend. Accounting for the effects of inflation, the demand base recedes at a rate of $-1.3 \%$ per annum. Aggregate growth prospects in Acornhoek are marginally positive and the demand base expands at $0.61 \%$ per annum. 
The area growth attributes are synthesized and graphically illustrated by means of the Growth Matrix (Figure 9 and 10). The Growth Matrix plots the combined effects of selected area growth variables, synthesized into two planes: a horizontal plane vertical plane in respect of market type (expanding or receding aggregate demand base) and consumer spend (increasing or decreasing real spend). Figure 9 illustrates the base matrix. Figure 10 illustrates the added effect of a suggested zonal overlay to aid interpretation.
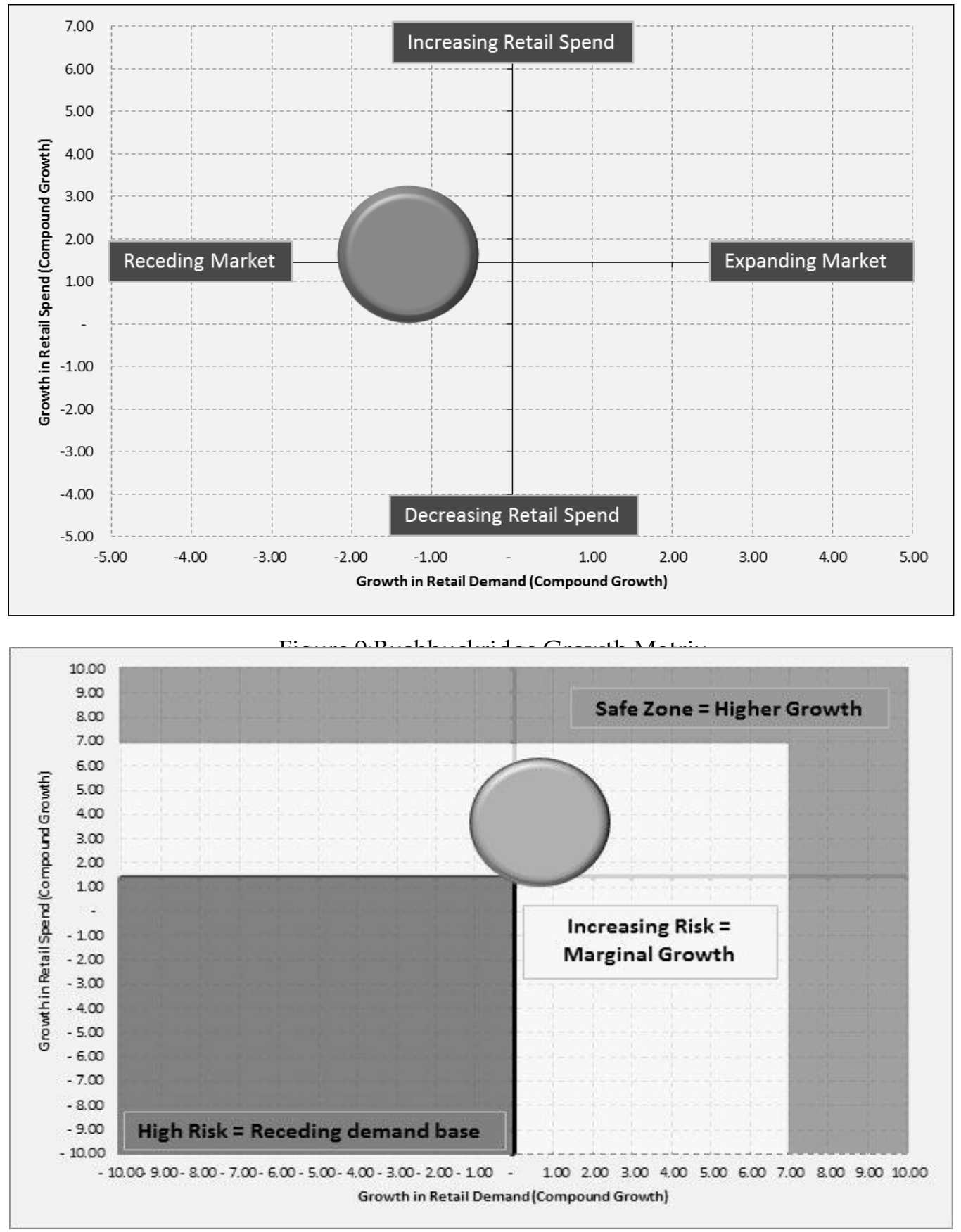

Figure 10:Acornhoek Growth Matrix

The suggested zonal overlays are summarized as follows:

Safe Zone. The desired result for a given center would be to achieve market based annual rental escalations of at least $7-8 \%$. This would locate a center in the safe zone of the growth matrix. 
Zone of Increasing Risk. Investor risk increases in this zone. Growth is positive but constrained.

High Risk Zone. The High-Risk Zone denotes market areas characterized by a receding long-term demand base. The area profile and growth attributes will not be able to sustain minimum rental escalations of 7 $8 \%$ per annum over the long term.

\section{Interpretation of Findings}

In terms of the multi-criteria saturation index (MCSI), the difference between the purchase power parity (PPP) adjusted floor space per capita parameter and its unadjusted counterpart, reveal the extent to which a market could accommodate future shopping center supply side densification. The difference between the two parameters highlight the inappropriateness of a comparison between markets with fundamentally different purchase power (and economic) characteristics, e.g. South Africa versus the United States.

In homogeneous markets the saturation index could be assumed to reflect the general state of the market. Conversely, in developing markets characterized by heterogeneous conditions and dualistic economic development tendencies (e.g. SA), demand potential will vary greatly according to localized conditions: pronounced idiosyncrasies can be expected to prevail between different cities and sub-regions. An analysis of trends in the floor space per capita parameter over time may offer additional insight into market conditions and future development prospects.

The RDI reflects on market structure and, more specifically, the internal organisation of market structure. In itself, the RDI does not indicate or denote market potential. The RDI provides an indication of the degree of diversity or, conversely, concentration. Inferences could be made regarding possible structural market gaps and development or redevelopment focus. Closer inspection of a particular market structure may also point towards maturity in certain segments which, in turn, should guide further investigation.

A higher RDI value indicates a concentrated market in which returns hinge on the performance of a limited number of dominant categories. Such overdependence may expose the market to certain vulnerabilities. Proportional dominance may also be indicative of oversupply in certain segments, which would serve as pointer for further analysis. A high RDI could be addressed through market diversification and redevelopment opportunities. Conversely, a lower RDI value indicates a proportionally more balanced and diversified retail market structure with income generating assets spread in a relatively more balanced manner across the spectrum. A market with a lower RDI value should be comparatively more resilient.

In either instance, the result is neutral and does not reflect on the quality of the retail environment or quality of market structure. The RDI simply denotes a state of market structure which may, on the one hand, render a particular market structure susceptible to certain risks and, on the other, open to certain opportunities. The RDI also does not appear to reflect directly on market age, although inferences could be drawn, based on the RDI value in relation to the general economic status of the region (Table 8).

Inter-regional comparison and selection are refined by means of trend surface mapping and more specifically the proposed demand density technique. The Demand Density Analysis for Mpumalanga Province in South Africa revealed visible spatial concentrations of demand density in administrative urban centers, industrial regions, mining towns and former homeland areas. A variety of GIS-based presentation techniques enabled the geographic localization of development opportunities for focused investigation.

Intraregional comparison is facilitated by means of the Growth Matrix. Findings of the Growth Matrix indicated that the areas of Bushbuckridge and Acornhoek, which pose a similar quantum of demand potential, reveal different socio-economic growth attributes. The aggregate effect of diverging growth attributes renders Acornhoek a marginally more appealing prospect for future retail sales growth and concomitant achievable rental escalations over time. Application of the Growth Matrix articulates the quantum of demand but may also inform an investor about aspects such as holding period of an asset.

The effects of decelerating income growth, rural to urban migration and a receding demand base over time have been masked by the artificial effects of government social grants and subsidies. The Growth Matrix reveals a gradually narrowing demand-supply gap in the greater Bushbuckridge area. 


\section{Conclusions}

Trade area analysis is a complex, multi-layered exercise that should be responsive to the multifaceted nature of the development environment - an environment in which more than demographics and local area planning policies shape the nature, extent and pace of development. The Multi-Criteria Saturation Index (MCSI) neutralises the effects of purchase power disparities between regions and, as such, facilitates inter-regional comparison. The Demand Density approach (DDA), in turn, is a GIS-based trend surface mapping technique that enables inter-regional comparison and area selection. The effects of complex socio-economic growth attributes that underlie a particular market area may have a significant bearing on asset performance and sustainability. To this end, the Growth Matrix (GM) assists in articulating the impact of trade area growth attributes on asset performance. A combination of these techniques enhances area selection and decisions associated with asset holding periods.

The above mentioned proposed analytical instruments have spatial capabilities when combined and may assist to enhance spatial analysis and modelling of market environments. Refinements to traditional market demand models to improve responsiveness to economic conditions are also advisable.

The research demonstrates that the application of a combination of techniques enhances market insight and articulates attributes of the retail environment that are not reflected through the application of traditional trade area analysis approaches.

The research furthermore highlights an important inherent limitation of simple per capita approaches. Progression, evolution and systematic retail network densification can be observed in developing (i.e. emerging) markets over time. In contrast, per capita methods tend to be applied in a rigid, inelastic manner - especially when applied by state entities to appraise development applications for e.g. shopping centres and hospitals. The rigid, inelastic application of per capita parameters creates a negative reinforcing phenomenon: i.e. by repeatedly applying the same (low) parameter, network growth and densification (i.e. evolution and progression) is inhibited and growth is inadvertently constrained.

The validity of the proposed measures is tested in Part II, in which the initial sales forecasts for a selection of twelve (12) new shopping centres in South Africa developed since 2007 are compared to actual centre sales performance.

\section{Research limitations and direction for further research}

Although every effort was made to enable the MCSI to be responsive to socio-economic differences between markets, the effects of the political economic environment was not directly factored. Aspects such as real estate ownership (i.e. property rights), or the absence thereof, may influence the appeal of a particular market to the investment fraternity, regardless of latent demand potential. The MCSI could potentially be refined to account for such risks.

Research could be expanded to cover a broader spectrum of countries. Longer term time series data collated over time could add further value to the techniques developed.

Comparatively higher floor space per capita parameters should prevail in urbanised areas and, conversely, lower floor space per capita parameters in rural areas. Refined research could assess the effects of, not only varying income, but also settlement density on floor space per capita parameters. The negative reinforcing phenomenon associated with parameter-based methods could also be addressed improvements to this method could possibly be affected by exploring the introduction of either a diminishing or increasing factor to adjust the parameter to more closely account for local idiosyncrasies, based on the growth attributes of the specific geographic market under investigation.

\section{References}

Applebaum W. \& S.B. Cohen. 1961. "The Dynamics of Store Trading Areas and Market Equilibrium." Annals of the Association of the American Geographer 51(1): 73 - 101.

Applebaum W. 1966. "Methods of Determining Store Trade Areas, Market Penetration and Potential Sales." Journal of Marketing Research 3(2): 127 - 141.

Box G.E.P. 1954. "The Exploration and Exploitation of Response Surfaces: Some General Considerations and Examples." Biometrics, 10 March: 16 - 60.

Chorley R.J. \& P. Haggett. 1968. "Trend-Surface Mapping in Geographical Research" in Brian J.L. Berry and Duane F. Marble, eds, Spatial Analysis: 195 - 217. Englewood Cliffs, NJ: Prentice Hall.

Christaller W. 1933. Die Zentralen Orte in Süddeutschland. Darmstadt. 
Clapp. J.M. 1987. Handbook for Real Estate Market Analysis. Prentice-Hall, In.: New Jersey.

Davies R.L. 1977. "Store Location and Store Assessment Research: The Integration of Some New and Traditional Techniques." Transactions of the Institute of British Geographers, New Series 2( 2): 141 - 157.

Dernburg T.F. 1985. Macroeconomics: Concepts, Theories and Policies. Seventh Edition. McGraw Hill Book Company: New York.

DiPasquale D. and W.C. Wheaton. 1996. Urban Economics and Real Estate Markets. Prentice-Hall Incorporated: New Jersey.

Director of Local Government, Transvaal Provincial Administration. 1982. Hierarchy of Business Centres. Unpublished.

Director of Local Government, Transvaal Provincial Administration. 1990. Hierarchy of Business Centres. Unpublished.

Gnos C. and L.P. Rochon. 2008. The Keynesian Multiplier. Routledge, England.

ICSC (International Council of Shopping Centres). 2016. Australia Country Fact Sheet for 2015. International Council of Shopping Centres: London.

ICSC (International Council of Shopping Centres). 2014. France Country Fact Sheet for 2014. International Council of Shopping Centres: London.

ICSC (International Council of Shopping Centres). 2016. Malaysia Country Fact Sheet for 2015. International Council of Shopping Centres: London.

ICSC (International Council of Shopping Centres). 2015. South Africa Country Fact Sheet for 2014. International Council of Shopping Centres: London.

ICSC (International Council of Shopping Centres). 2016. Turkey Country Fact Sheet for 2015. International Council of Shopping Centres: London.

ICSC (International Council of Shopping Centres. 2016. United States of America Country Fact Sheet for 2016. International Council of Shopping Centres: London.

ICSC (International Council of Shopping Centres). 2016. China Country Fact Sheet for 2015. International Council of Shopping Centres: London.

Kiel G. \& G. Haberkern. 1998. "Issues in Shopping Centre Trade Areas, Theory and Practice". Theory E Practice: 1138 1154. Graduate School of Management, The University of Queensland: Brisbane.

Lombard J.A., J.Z. Du Pisani, and F.G. Steyn. 1986. Theoretical Foundations of the Political Economy. Southern Boekuitgewers: Bergvlei.

Lombard J.A., J.J. Stadler, and P.J. Haasbroek. 1989. The Economic System of South Africa. HAUM Educational Publishers: Pretoria.

Nicolas G. 2009. “Walter Christaller from ‘exquisite corpse' to 'corpse resuscitated." S.A.P.I.E.N.S. 2(2) Special Issue: 1 - 29. Institut Veolia Environment.

Perales R.C. 2002. "Consumer Choice in Competitive Location Models". PhD diss., Department d'Econnomia i Empresa Tesi Doctoral: Universitat Pompeu Fabra.

Peterson R.A. 1974. “Trade Area Analysis Using Trend Surface Mapping.” Journal of Marketing Research 11(3): 338 342.

Pyhrr S.A., J.R. Cooper, L.E. Wofford, S.D. Kapplin and P.D. Lapides. 1989. Real Estate Investment. Strategy, Analysis, Decisions. Second edition. Wiley: New York.

Timmermans H. 1993. "Retail Environments and Spatial Shopping Behaviour." Chapter 14 in Behaviour and Environment: Psychological and Geographical Approaches: 342 - 377, Elsevier Science Publishers. 